\section{Good Agricultural Practices in Australia and Southeast Asia}

\author{
Robert Premier ${ }^{1}$ and Scott Ledger ${ }^{2}$
}

ADDITIONAL INDEX WORDs. quality assurance, hazard analysis critical control point

SUMMARY. Quality assurance (QA) in the horticultural industry has become well established in Australia; on-farm hazard analysis critical control point (HACCP)based plans have been adopted due to pressures from supermarkets and other buyers, including fresh markets. Supermarkets' own systems and more general QA systems have been used by growers to meet these new requirements. Two QA systems, Freshcare and Safe Quality Food, have been introduced across the country with moderate success. A review of quality assurance parameters such as chemical residues and microbiological contaminants suggest that these QA systems have achieved some level of assurance. Local pressures, however, are not the only concern when it comes to QA. International demand for safe quality fruit and vegetables has meant that $Q A$ systems now need to be designed to satisfy export requirements. In addition to food safety, international demands must also address the environment and workers' health and safety. Many Southeast Asian governments have taken the initiative and developed country-specific QA systems to satisfy export markets and that are suitable for their farmers to use. Countries with schemes in place include Malaysia, Thailand, Indonesia, and Singapore, with other countries, such as the Philippines and Brunei Darussalam, in the process of introducing schemes. This presentation will discuss the status of QA systems in Australia and Southeast Asia, including the pressures behind their establishment, and the major differences between them. The presentation will also focus on the attempt by Southeast Asian governments to address a uniform standard through the development of the Association of Southeast Asian Nations (ASEAN) good agricultural practice (GAP), a GAP standard suitable for use by all 10 ASEAN member countries.

$\mathrm{O}$ ver the past few years we have seen the introduction of GAP in a number of countries. This has occurred and is occurring for different reasons and for different purposes. Driven mainly by food safety requirements, GAP has been introduced to growers of fruit and vegetables in different forms. Australia was perhaps one of the first countries that ventured into this field. Food safety-based quality assurance plans were widely introduced at "on-farm" level as early as 1998. The introduction of QA plans was seen by many farmers as an obligation they had to achieve in order to meet existing markets, mainly to supermarket buyers. Many growers begrudgingly implemented these plans at great costs. Initial plans were expensive to introduce, as consultants in this area were relatively hard to find. The cost of maintaining these plans was also high, with a devoted QA manager usually being employed by the larger farms or an ongoing consultant employed by smaller farming operations. Added to

${ }^{1}$ Department of Primary Industries, Victoria, Australia.

${ }^{2}$ Queensland Department of Primary Industries and Fisheries. this cost was the expensive third-party auditing fee that was required at regular intervals. These plans were mainly based on either supermarket-based QA plans or on Safe Quality Food (SQF) (SQF Institute, 2004), a QA plan that was developed by the Western Australia Department of Agriculture. Importantly, these QA plans and their cost led to many growers resisting a more general adoption of QA plans for non-supermarket supplies. A team of experts from each of the Australian states lead by the Queensland Department of Primary Industry decided to develop a very simple food safety-based QA program, called the "Approved Supplier Program." It consisted mainly of a simple set of instructions for the grower with a checklist that assisted the grower to systematically go through the practices in place in the farm. This document was of high quality and was industry.

The guide included growing and handling practices that a customer may require of suppliers as part of their approved supplier program. The practices were not considered mandatory, but as options for customers and suppliers distributed widely in the horticultural to consider. Customers would discuss their requirements with their suppliers and agree on practices that were practical and achievable, and consistent with the level of risk to food safety and quality.

Requirements for practices varied depending on the type of produce, the production system and on customer needs. Practices could be added to or deleted from the guide to suit each customer and supplier arrangement.

The guide addressed significant food safety and quality hazards to fresh produce. The guide also took into account that some customers in the future may require control of other hazards such as environmental impacts and occupational health and safety.

Section 3 of the guide contained a checklist of practices to consider when developing an approved supplier program. The practices were grouped into five sections: 1) product and handling specifications, 2) product identification and traceability, 3 ) training, 4) controlling quality hazards, and 5 ) controlling food safety hazards.

Section 4 of the guide contained further information to explain what was required for each practice. The appendices contained reference information and examples of some documents mentioned in the guide.

This guide, however, did not satisfy supermarkets' needs, as it had no element of third-party auditing. To satisfy this shortcoming, the guide was reworked consequently and expanded mainly through the hard work of the Queensland Department of Primary Industry and Fisheries, Growcom [ formerly Queensland Fruit and Vegetable Growers (QFVG)], and AUS-QUAL (AUS-QUAL Pty. Ltd, Brisbane, Australia) to become the Freshcare system (Freshcare, 2004). Freshcare is an industry owned QA system that is simple to implement and is effective to administer with a number of registered companies being able to audit to the Freshcare standards. This third-party auditing satisfies supermarket requirements. The Freshcare program offers benefits to both suppliers and customers. It provides verification that an industry-recognized food safety program is followed. Certification to the Freshcare program is achieved through independent auditing to the code of practice. The Freshcare Code of Practice is an industry-owned standard, describing the practices required 
on-farm to provide assurance that fresh produce is safe to eat and has been prepared to meet customer specifications where they exist.

The Freshcare Code of Practice covers practices required to: prevent or minimize food safety hazards occurring during growing, harvesting, handling, packing, storage, and transport of fresh produce; prepare produce to customer specifications; identify, trace, and withdraw/recall produce; and manage staff and documentation, and review compliance.

Freshcare is the horticultural industry's own on-farm food safety program, developed by industry, for industry, and operated as a "not for profit" organization.

Freshcare is owned by 18 peak industry bodies: Apple and Pear Australia Limited (APAL), Australian Avocado Growers Federation, Australian Banana Growers Council, Australian Chamber of Fruit and Vegetable Industries Ltd., Australian Custard Apple Growers Association Inc., Australian Fresh Stone Fruit Growers Association, Australian Lychee Growers Association Inc., Australian Mango Industry Association Ltd., Australian Melon Association, Australian Mushroom Growers Association, Australian Passionfruit Industry Association Inc. (APIA), Australian Potato Industry Council Inc., Australian United Fresh Fruit and Vegetable Association Ltd., Australian Vegetable and Potato Growers Federation Inc. (Ausveg), Growcom, Victorian Farmers Federation Horticulture Group, New South Wales Farmers' Association, and the South Australia Farmers Federation. The owner organizations provide a vital link and conduit for information between Freshcare and their individual members.

The requirements of the Freshcare Code of Practice, called elements, are grouped into three sections: management, chemicals, and fresh produce. Each element describes the outcomes required and the steps necessary to ensure compliance. The first two sections, management and chemicals, contain elements common to the Cattlecare, Flockcare, and Graincare Codes of Practice. The third section, fresh produce, contains elements specific to fresh produce.

Under element one, management, there are sections on training, internal auditing and corrective action, records and document control. Under element two, chemicals, there are sections on persistent chemicals, obtaining, storing and disposing of chemicals, chemical treatments and chemical testing. Under section three, fresh produce, there are sections on product and handling specifications, product identification, traceability and recall, fertilizers and soil additives, water use, site and premises, equipment, containers and materials, cleaning and vermin control, personal hygiene, storage ripening and transport and lastly, other practices.

Another major QA system used in Australia for fresh produce is the SQF system. Originally developed by the Western Australia Departments of Agriculture but now privately owned, SQF was introduced very early on in many Australian states; in the State of Victoria many growers adopted the SQF 2000 QA system. The SQF code is now managed by the Food Marketing Institute (Washington, D.C.). Two codes are used in horticulture: the SQF 1000 code applies only to primary production while the SQF 2000 code applies to any type of business, including primary production and packing facilities. Both codes cover food safety and quality hazards and each code has three certification levels. At the highest level (level 3), a HACCP plan must be developed, validated and verified by a SQF Expert.

SQF 2000 and SQF 1000 have recently gained recognition from the Global Food Safety Initiative (GFSI). GFSI was launched in 2000 by a group of international retailers with the purpose of establishing product-linked standards for food safety covering the whole food chain: supplier, agriculture, distribution (CIESnet, 2006). These standards can then be used by the retailers as reference standards, which must be met by suppliers. There are businesses certified to SQF 2000 in the U.S., Japan, Thailand, and a number of other countries. SQF 1000 and SQF 2000 are acceptable for direct and indirect suppliers to Coles supermarkets (Coles Myer Ltd., Melbourne, Australia) and indirect suppliers to Woolworths supermarkets (Woolworths Ltd., Sydney, Australia), the two major supermarket chains in Australia.

In addition to these programs, there are many relevant documents that are important in the area of GAP in Australia. There are food safetyspecific guides for the vegetable in- dustry, fresh cut industry, strawberry (Fragaria $\times$ ananassa) industry, and packing sheds. The most important of these guides is the Australian Government sponsored "Guidelines for on-farm food safety for fresh produce" (Australian Government, Department of Agriculture, Fishery and Forestry, 2006). These guidelines are designed to help assess the risk of food safety hazards occurring during production on-farm for fresh produce crops, and provide information on the GAP needed to prevent, reduce, or eliminate the hazards. The practices have been identified from industry food safety programs based on the HACCP method.

Food safety hazards covered by these GAP guidelines included any biological, chemical, or physical substance or property that can cause produce to become an unacceptable health risk to consumers. Fresh produce includes fruit, vegetables, herbs, and nuts; and production covers the growing, harvesting, packing, storage, and dispatch of produce to customers.

These guidelines were designed for use by growers, trainers, facilitators, auditors, and customers to achieve greater certainty and consistency in the development, implementation, and auditing of on-farm food safety programs.

\section{GAP in Southeast Asia}

Recent developments in international trade have highlighted the need for exporting countries to pay due diligence in the field of food safety and quality assurance. The developments are described in the Food and Agriculture Organization of the United Nations (FAO) strategy for a food chain approach to food safety (FAO, 2003).

There is a need for producing countries to fully understand these trade requirements and to implement standards that cover at least the basic requirements for a food safety-based QA plan. This should cover both microbiological issues and chemical contaminating issues addressing pesticide residues and maximum residue limits (MRL) applicable to the country with due regard to potential export market requirements. The problem facing the smaller exporting countries at the moment is that strong importing countries like the European Union (EU) and the U.S. are forcing their 
own standards on exporters because there are no others in place. EU standards may not be fully suitable for developing countries involved in tropical and subtropical horticulture; the EU does not operate in this type of climate nor does it operate in this type of environment or socioeconomic framework.

It is important for countries to consider their options to fulfil quality requirements. GAP specific for a region will be sufficient to cover food safety aspects at all stages of farming operations from pre-planting, planting, growing, harvesting, storage, and transport. QA systems based on food safety can also assist with quality issues including postharvest quality.

Southeast Asian countries, especially members of ASEAN-Malaysia, Thailand, Singapore, Indonesia, Philippines, Brunei Darussalam, Cambodia, Myanmar, Vietnam, and Laos PDR - face an interesting problem. Each has developing international export markets, some for specific food crops such as jackfruit (Artocarpus heteropyllus), mangosteen (Garcinia mangostana), starfruit (Averrhoa carambola), and dragonfruit (Hylocerus undatus). These international export markets are only part of the story. There is a substantial and increasing internal trade within the ASEAN block. This trade will continue to rise as ASEAN approaches its 2020 vision of a common market.

In response to international trade requirements some Southeast Asian countries have already introduced QA systems that include elements of GAP. Malaysia has introduced the farm accreditation scheme called the "skim akreditasi ladang Malaysia" (SALM) system (Malaysian Government, 2002). This is a program to recognize farms that adopt GAP, operate in a sustainable and an environmentally friendly way, are sensitive to workers' welfare, and produce safe, good quality products. SALM is based on inspection and verification of farm and farming practices by external auditors.

Farms are audited for compliance to accepted and defined protocols, national guidelines, standards, legislation, and policies. Benchmarking on specific farm practice is based on national standards, policies and legislation, trade standards such as EurepGAP (EurepGAP, 2004), or international standards such as Codex
Alimentarius standards. There are 17 major conditions that are examined as part of SALM certification: 1) legal entity, 2) soil inspection report, 3 ) suitable soil and terrain, 4) elevation less than $1000 \mathrm{~m}(3280.8 \mathrm{ft}), 5)$ soil conservation measures, 6 ) farm records, 7 ) approved fertilizers, 8 ) non-genetically modified (GMO) planting materials, 9) registered pesticides, 10) integrated pest management (IPM), 11) protective clothing for workers, 12) storage facilities for inputs, 13) harvesting management system, 14) legal workers above 16 years of age, 15 ) proper waste disposal, 16) pesticide residues below MRL, 17) heavy metal contents below permitted level

Farms that are accredited receive certification and allowed to use the SALM logo.

Malaysia's reason for introducing the SALM system is two-fold: first, for internal sales but second and more importantly, for sales to other ASEAN countries like Singapore and for exports to non-ASEAN countries.

Thailand has also tried to address the introduction of GAP based on quality and food safety (Asian and Pacific Centre for Agricultural Engineering and Machinery, 2005). They have introduced the Plant Quality Management System. This comprises three distinct sections: GAP for on-farm quality management, a quality management system for packinghouses, and a quality management system for processing of plant foods. The GAP includes elements of water quality, field and land history, pesticide issues, on-farm stocking and transport, crop protection, production process, postharvest, and record keeping. They have developed product-specific manuals that include quality specifications and plans and food safety GAP for on-farm for over 30 different individual products. They have been introducing this quality management system to over 325,000 farms and they hope to have at least $5 \%$ certified before the end of 2005. The advisory body responsible for advice in this area is the Department of Agricultural Extension. The certification body is the Department of Agriculture and the accreditation body is the National Bureau of Agricultural Commodities and Food Standards.

Other Southeast Asian countries have introduced schemes based on GAP for food safety; this includes the vegetable farmers' GAP in Singapore and the IndonGAP in Indonesia. Philippines is currently considering the introduction of a scheme based on GAP.

Under a project funded by the ASEAN Australia Development Cooperation Program, a standard for ASEAN GAP has been developed to harmonize GAP programs in the region (ASEAN Postharvest Horticulture Network, 2004). The goal is to facilitate trade between ASEAN countries and to global markets, improve viability for farmers, and help sustain a safe food supply and the environment. ASEAN GAP is an umbrella standard that individual member countries will benchmark their national programs against to gain equivalence. The scope of ASEAN GAP covers the production, harvesting, and postharvest handling of fresh fruit and vegetables on-farm and postharvest handling in locations where produce is packed for sale. ASEAN GAP consists of four modules covering food safety, environmental management, worker health, safety and welfare, and produce quality. Each module can be used alone or in combination with other modules. This enables progressive implementation of ASEAN GAP, module by module based on individual country priorities. New ASEAN member countries, such as Cambodia, Laos PDR, Myanmar, and Vietnam, may also find the staged introduction of GAP in module form a better option.

There is no doubt that there is some element of confusion as to what a GAP is. In essence, these are a collection of principles to apply for on-farm production and post-production processes, resulting in safe and healthy food and non-food agricultural products, while taking into account economical, social, and environmental sustainability. A successful GAP requires gaining and maintaining an understanding of production techniques and production systems for each of the major agroecological area (ecoregion).

Thus, the aim in development of suitable GAP is to collect, analyze, and disseminate information of good practices in relevant geographical contexts; it should include anything that increases responsible farming practices related to food safety to protect consumers; environmental issues that protect soil, water, air, native vegetation, and animals; sustainability 
of the operations; and workers' health and safety.

The drivers for the introduction of GAP are different from country to country but the ultimate aim is to produce agricultural foods that are safe to eat, in an environmentally friendly manner, and by a workforce that remains economically viable and safe.

\section{Literature cited}

Association of Southeast Asian Nations Postharvest Horticulture Network. 2004. ASEAN GAP. 10 June 2006. <http:/ / www. aphnet.org/gap/ASEANgap.html>.

Asian and Pacific Centre for Agricultural Engineering and Machinery. 2005. Quality management system: Good agricultural practice (GAP) in Thailand. 10 June 2006. <http://www.unapcaem. org/Activities\%20Files/A22/p79_QualityMgr.pdf $>$.

Australian Government Department of Agriculture, Fishery and Forestry. 2006. Australian guidelines for on farm food safety. 10 June 2006. <http://www.daff. gov.au/content/publications.cfm?Categ ory=Agricultural $\% 20$ Industries\%20and $\%$ 20Food\&ObjectID =E983F36E-534C45CA-94E04359AB7B00DE>.

CIESnet, The Food Business Forum. 2006. Global food safety initiative. June 10 2006. <http://www.ciesnet.com/pfiles/ programmes/foodsafety/GFSI_Guidance_Document_4th_edition.pdf>.

EurepGAP. 2004. General regulations, fruit and vegetables. 10 June 2006. <http://www.eurepgap.org/documents/ webdocs/EUREPGAP_GR_FP_V21Oct04_update_08Jun06.pdf>.

Food and Agriculture Organization of the United Nations. 2003. Committee on Agriculture, Seventeenth session. 10 June 2006. <http://www.fao.org/DOCREP/ MEETING/006/Y8350E.HTM>.

Freshcare. 2004. On farm food safety program for fresh produce. 10 June 2006. <http://www.freshcare.com.au/directory $/$ shop .asp? site $=303>$.

Malaysian Government. 2002. Skim akreditasi ladang Malaysia. I Jan. 2006. <http://agrolink.moa.my/doa/ Аpa\%20dia\%20SALM.htm>.

SQF Institute. 2004. Safe Quality Food 2000. 10 June 2006. <http://sqfi.com/ documentation/SQF2000_Code.pdf>. 